\title{
Pharmacological and Biological Effects of Tin- Protoporphyrin on Neonatal Hyperbilirubinemic Gunn Rats
}

\author{
HIDETOSHI NAGAE, HIROOMI KEINO, KAZUYOSHI WATANABE, AND \\ SHIGEO KASHIWAMATA
}

Department of Pediatrics, Nagoya University School of Medicine, Showa-ku, Nagoya [H.N., K.W.] and Department of Perinatology, Institute for Developmental Research, Aichi Prefecture Colony, Kamiya-cho, Kasugai, Aichi [H.K., S.K.], Japan

\begin{abstract}
Our study was undertaken to examine the pharmacological and biological effects of tin-protoporphyrin, a competitive inhibitor of heme oxygenase, on 5or 6-day-old homozygous $(j / j)$ Gunn rats with hereditary unconjugated hyperbilirubinemia. When $j / j$ neonates were injected subcutaneously with $20 \mu \mathrm{mol}$ of tin-protoporphyrin/kg of body weight, hepatic heme oxygenase activity decreased to $30 \%$ of the initial level $2 \mathrm{~h}$ after administration and remained low during the next $46 \mathrm{~h}$. However, the reduction of serum bilirubin was more rapid and transient, reaching the minimum value $(40 \%$ of the initial level) at 1 $h$ and increasing thereafter at a rate almost comparable to that in nontreated $j / j$ rats. The mortality rate of $j / j$ rats was strikingly reduced by the administration of 1 to 100 $\mu \mathrm{mol}$ of tin-protoporphyrin/kg; the most effective dose was $5 \mu \mathrm{mol} / \mathrm{kg}$ ( $8 \%$ compared with $80 \%$ in non-treated $j / j$ rats). However, the protective effect of tin-protoporphyrin on bilirubin cerebellopathy (cerebellar hypoplasia) was less marked than expected. Possible implications of our results are discussed. (Pediatr Res 24: 209-912, 1988)
\end{abstract}

\section{Abbreviations}

SnPP, tin-protoporphyrin

$j / j$, homozygous to the jaundice gene

$j /+$, heterozygous to the jaundice gene

$\mathrm{Ki}$, inhibition constant

Hyperbilirubinemia remains a significant problem in human neonates. Phototherapy and exchange transfusion are current therapies widely used for neonatal jaundice. However, there is an increasing number of surviving extremely low birth weight infants in whom these therapies may not be effective. Several drugs have been used to reduce the total serum bilirubin level in neonates $(1,2)$, but these carry significant risk (3).

Drummond and Kappas (4) reported the chemoprevention of neonatal jaundice by SnPP. This compound is a potent competitive inhibitor of microsomal heme oxygenase, a rate-limiting enzyme in the degradation of heme to bilirubin. SnPP amelio-

Received December 14, 1987; accepted April 7, 1988

Correspondence Hidetoshi Nagae, M.D., \% Department of Perinatology, Institute for Developmental Research, Aichi Prefecture Colony, 713-8 Kamiya-cho Kasugai, Aichi 480-03, Japan.

Supported in part by Grant 60A-2 from National Center for Neurology and Psychiatry of the Ministry of Health and Welfare, by Grant-in-Aids from the Ministry of Education, Science and Culture (61304060, 62480226 and 62570446), and by Grant 61-342 from the Ishida Foundation, in Japan. rates developing hyperbilirubinemia in newborn rats $(4,5)$ and rhesus monkeys (6) and reduces the plasma bilirubin level in adult mutant mice with hemolytic anemia $(7,8) . j / j$ Gunn rats with an inherited deficiency of hepatic bilirubin:uridine diphosphate-glucuronyltransferase activity (9) are hyperbilirubinemic throughout life (10) and develop bilirubin-induced cerebellar hypoplasia $(11-14)$. In our study we evaluated the pharmacological and biological effects of SnPP in this rat model of neonatal jaundice.

\section{MATERIALS AND METHODS}

$j / j$ and apparently normal $j /+$ Gunn rats of the SpragueDawley strain, developed in our laboratory (14), were used in our study. The breeding conditions were as reported previously (14). The litter size was restricted to eight pups soon after delivery. SnPP was purchased from Porphyrin Products (Logan, UT). All other chemicals used were of the highest grade commercially available. SnPP was dissolved in a small volume of $0.1 \mathrm{~N} \mathrm{KOH}$, the $\mathrm{pH}$ was adjusted to 7.4 with $0.1 \mathrm{~N} \mathrm{HCl}$, and the solution was diluted to desired concentrations with $0.1 \mathrm{M}$ phosphate buffer, $\mathrm{pH}$ 7.4. All solutions were prepared under dim light just before use. SnPP was administered subcutaneously to $j / j$ and $j /+$ rats at various doses up to $100 \mu \mathrm{mol} / \mathrm{kg}$ of body weight.

Treated and nontreated adult rats were anesthetized with chloroform and perfused in situ with ice-cold physiological saline. Livers and spleens were excised and homogenized in a Teflon-pestled glass homogenizer with 3 vol of $50 \mathrm{mM}$ Tris-Cl buffer, $\mathrm{pH} 7.4$, containing $0.25 \mathrm{M}$ sucrose. The homogenate was centrifuged at $18,000 \times g$ for $10 \mathrm{~min}$. The supernatants from the livers and spleens of $j /+$ rats, and from the spleens of $j / j$ rats were used to assess the kinetic parameters of heme oxygenase. In the case of the $j / j$ rat livers, the microsomal fraction was analyzed because of a very high concentration of bilirubin in the $18,000 \times g$ supernatant. The microsomal pellet, obtained by centrifuging the supernatant at $105,000 \times g$ for $60 \mathrm{~min}$, was resuspended in $50 \mathrm{mM}$ Tris- $\mathrm{Cl}$ buffer, $\mathrm{pH} 7.4$, containing 0.25 $\mathrm{M}$ sucrose.

Heme oxygenase activity was measured by the method of Tenhunen et al. (15). The reaction mixture $(2.1 \mathrm{ml})$ contained $18,000 \times g$ supernatant $(1.2$ to $2.6 \mathrm{mg}$ of protein); $41.7 \mu \mathrm{M}$ methemalbumin (16); $270 \mu \mathrm{M} \mathrm{NADPH}{ }_{2}$; and $90 \mathrm{mM}$ potassium phosphate buffer, $\mathrm{pH} 7.4$, bubbled with $\mathrm{O}_{2}$ just before use. To measure enzymatic activity in the $j / j$ rat liver, the $18,000 \times g$ supernatant was replaced by a microsomal suspension $(0.15$ to $0.47 \mathrm{mg}$ of protein), and the $105,000 \times \mathrm{g} / 60 \mathrm{~min}$ supernatant (2.3 $\mathrm{mg}$ of protein) from the $j /+$ rat liver was included as a source of biliverdin reductase. The reaction mixture was incubated at $37^{\circ} \mathrm{C}$ for $10 \mathrm{~min}$. Bilirubin formed during the incubation 
was extracted by the method of Katoh et al. (17)-a 1.8-ml aliquot of the reaction mixture was transferred into $5.25 \mathrm{ml}$ of an ice-cold chloroform-methanol solution $(2: 5$, vol/vol), followed by the addition of $3 \mathrm{ml}$ of cold distilled water. After shaking the mixture vigorously for $20 \mathrm{~s}$, the organic phase was separated by centrifugation at $1000 \times g$ for $10 \mathrm{~min}$ at room temperature.

Bilirubin extracted was calculated from the difference between absorbances at 452 and $520 \mathrm{~nm}$ by using a molecular extinction coefficient at $452 \mathrm{~nm}$ of 62,600 (17). All procedures were carried out under dim light. The amount of bilirubin formed was linear with respect to incubation time or protein concentration under the conditions used. The specific activity was expressed as nmol of bilirubin formed $/ \mathrm{mg}$ of protein $/ 10 \mathrm{~min}$. Protein was estimated by the method of Lowry et al. (18) using crystalline bovine serum albumin as a standard. The total serum bilirubin concentration was determined according to the method of Malloy and Evelyn (19). Group mean comparisons were made by the $t$ test or alternatively a modified $t$ test (the Cochran and Cox method) when group variances were unequal.

\section{RESULTS}

Figure 1 shows representative double reciprocal plots of splenic heme oxygenase activity versus methemalbumin (substrate) with and without SnPP in adult $j /+$ rats. The two lines converged to almost the same point on the ordinate, which is consistent with previous reports that $\mathrm{SnPP}$ is a competitive inhibitor with respect to the substrate $(4,5)$. Apparent $\mathrm{Km}$ values for methemalbumin were calculated to be 33.4 and $7.3 \mu \mathrm{M}$ in the presence and absence of the inhibitor, respectively. Table 1 summarizes kinetic parameters obtained from four separate experiments with enzyme preparations from the spleen and liver of $j /+$ and $j / j$ adult rats. The competitive nature of SnPP inhibition with regard to the substrate was common in all cases. Although some variations were observed in $\mathrm{Km}$ values for the substrate among four enzyme sources, they were not greatly different from each other. This was also true of apparent inhibition constants $(K i)$ for SnPP.

As shown in Figure 2, hepatic heme oxygenase activity in $j / j$ neonates decreased rapidly after administration of SnPP to a minimum value, 2 h later. Enzyme activity increased gradually thereafter to about two-fifths of the initial level at $48 \mathrm{~h}$. The response of serum bilirubin to SnPP is demonstrated in Figure 3. Reduction in the concentration of serum bilirubin was rapid and transient. One $h$ after SnPP treatment the bilirubin level decreased about $60 \%$ but increased steadily thereafter at a rate comparable to that in nontreated $j / j$ rats.

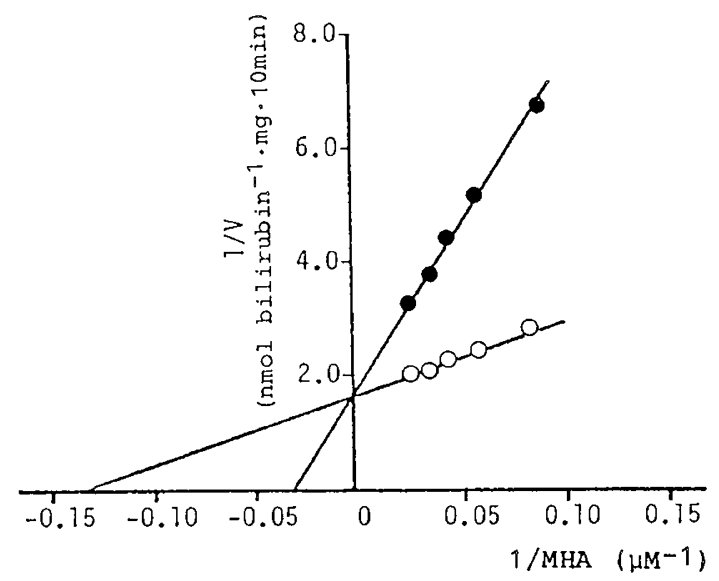

Fig. 1. Double reciplocal plots of heme oxygenase activity $(V)$ versus methemalbumin $(M H A)$ in the presence $(\bullet)$ and absence $(O)$ of $0.2 \mu \mathrm{M}$ tin-protoporphyrin. The microsomal fraction prepared from the spleen of adult heterozygous Gunn rats was used as an enzyme source. Each point represents the average of triplicate determinations.
Table 1. Apparent Km for methemalbumin and Ki for SnPP in heme oxygenase reactions in spleen and liver of adult heterozygous (j/+) and homozygous (j/j) Gunn rats*

\begin{tabular}{llcl}
\hline & $n$ & $\mathrm{Km}(\mu \mathrm{M})$ & $\mathrm{Ki}(\mathrm{nM})$ \\
\hline$j /+$ spleen & 3 & $6.1 \pm 0.76$ & $40.6 \pm 10.8$ \\
$j / j$ spleen & 4 & $12.0 \pm 3.0$ & $45.0 \pm 4.1$ \\
$j /+$ liver & 3 & $13.8 \pm 2.5$ & $33.8 \pm 2.4$ \\
$j / j$ liver & 4 & $14.0 \pm 0.7$ & $20.3 \pm 4.5$ \\
\hline
\end{tabular}

* Results are expressed as the averages $\pm \mathrm{SD}$ of the indicated number $(n)$ of rats. Experimental details refer to "Materials and Methods." $\mathrm{Km}$ values for methemalbumin were determined from the double reciprocal plots of enzymic activity versus methemalbumin. Ki values for SnPP were calculated from the plots of SnPP concentration versus slope obtained from the double reciprocal plots in the presence and absence of SnPP.

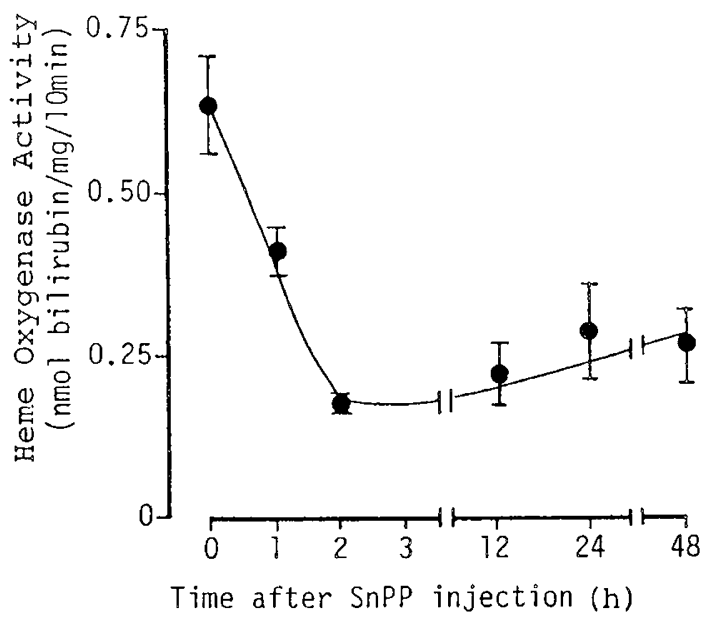

Fig. 2. Time course of hepatic heme oxygenase activity after subcutaneous administration of $20 \mu \mathrm{mol}$ of $\mathrm{SnPP} / \mathrm{kg}$ of body weight to 6-dayold homozygous Gunn rats. For experimental details refer to "Materials and Methods." Each point represents the average $\pm \mathrm{SD}$ (bar) of two to five rats.

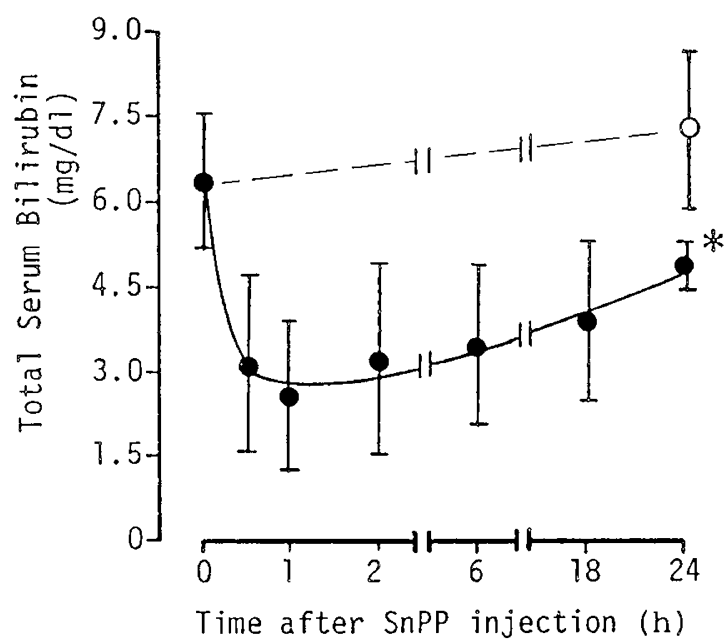

Fig. 3. Time course of the concentration of serum bilirubin after subcutaneous administration of $20 \mu \mathrm{mol}$ of SnPP/ $\mathrm{kg}$ of body weight to 6-day-old homozygous Gunn rats. Blood was collected from the tail vein of each rat according to the schedule. The open circle shows the average concentration of serum bilirubin in nontreated homozygous Gunn rats at 7 days of life $(n=12)$. Each closed circle represents the average \pm SD (bar) of eight littermates. ${ }^{*} p<0.01$ compared with nontreated rats at 7 days of life. 
Various doses of $\operatorname{SnPP}(0.5-100 \mu \mathrm{mol} / \mathrm{kg}$ of body weight $)$ were tested to evaluate in vivo effects on the rate of mortality and cerebellar development in jaundiced neonates. As shown in Table 2 there were no differences between the morality rates of SnPPtreated and nontreated $j /+$ rats. However, mortality was reduced in $j / j$ rats injected with 1 to $100 \mu \mathrm{mol}$ of SnPP $/ \mathrm{kg}$ of body weight. The most effective dose was $5 \mu \mathrm{mol} / \mathrm{kg}$ of body weight. Although the cerebellar wet weight of any group of $j /+$ rats treated with SnPP did not differ significantly from that of the nontreated control group, the cerebellar weights of the $j / j$ rat groups given 1 and $5 \mu \mathrm{mol}$ of drug $/ \mathrm{kg}$ were significantly increased (by 51 and $45 \%$, respectively) over the control value (Table 2 ).

\section{DISCUSSION}

The present kinetic study demonstrates that heme oxygenases prepared from liver and spleen have similar affinity for heme or SnPP between in the $j /+$ and $j / j$ Gunn rats. The apparent $\mathrm{Km}$ values for heme of hepatic and splenic enzymes were within the range reported previously for microsomal preparations from human (4) and rat (15) spleens, or rat liver (5). The $\mathrm{Ki}$ values for $\mathrm{SnPP}$ also were similar to values in previous reports $(4,5)$. Thus the heme oxygenase characteristics in liver and spleen were similar in nature independent of genotype.

As shown in several in vivo studies (4-8), the administration of SnPP to $j / j$ neonates causes rapid decreases in hepatic heme oxygenase activity and serum bilirubin. However, the reduction of serum bilirubin occurred within $60 \mathrm{~min}$ after SnPP administration, whereas the decrease in hepatic heme oxygenase activity continued for $2 \mathrm{~h}$ with a trend similar to that reported by Anderson et al. (20). This is also recognized in the data reported previously $(21-23)$. Furthermore, the recovery of serum bilirubin was much faster than that of enzymatic activity. It has been reported that the biological half-life of bilirubin in $j / j$ Gunn rats is 33 to $62 \mathrm{~h}$ (24). Accordingly, even if heme oxygenase activity is completely blocked in vivo by SnPP, the serum bilirubin level would be expected to decrease more gradually than we observed.

There are several possible explanations about the observed phenomenon. SnPP may interfere with the bilirubin measurement. To assess this possibility, SnPP was mixed with the $j / j$ rat serum at various concentrations $(1-50 \mu \mathrm{M})$, and bilirubin assayed as described in "Materials and Methods." No interference

Table 2. In vivo effects of SnPP on mortality rate and cerebellar wet wt in $j /+$ and $j / j$ Gunn rats*

\begin{tabular}{ccccc}
\hline Rat & $\begin{array}{c}\text { SnPP } \\
(\mu \mathrm{mol} / \mathrm{kg} \\
\text { of body wt) }\end{array}$ & $\begin{array}{c}\text { No. of } \\
\text { rats used }\end{array}$ & $\begin{array}{c}\text { Mortality } \\
\text { rate }(\%)\end{array}$ & $\begin{array}{c}\text { Cerebellar } \\
\text { wet wt }(\mathrm{mg})\end{array}$ \\
\hline$j /+$ & 0 & 32 & 9 & $215.8 \pm 14.6$ \\
& 0.5 & 14 & 14 & $198.6 \pm 5.5$ \\
& 1 & 6 & 0 & $237.0 \pm 7.5$ \\
& 5 & 3 & 0 & $240.0 \pm 3.5$ \\
& 10 & 4 & 0 & $236.2 \pm 7.6$ \\
& 20 & 6 & 0 & $223.6 \pm 5.9$ \\
& 50 & 6 & 17 & $212.3 \pm 7.4$ \\
& 100 & 6 & 17 & $228.5 \pm 8.3$ \\
& 0 & 70 & 80 & $49.9 \pm 9.5$ \\
& 0.5 & 26 & 73 & $53.4 \pm 8.0$ \\
& 1 & 10 & 20 & $75.1 \pm 9.9 \dagger$ \\
& 5 & 13 & 8 & $72.1 \pm 10.7 \dagger$ \\
& 10 & 12 & 25 & $68.2 \pm 19.3$ \\
& 20 & 10 & 40 & $57.3 \pm 5.6$ \\
& 50 & 10 & 30 & $55.5 \pm 7.3$ \\
& 100 & 10 & 30 & $50.3 \pm 3.8$ \\
\hline
\end{tabular}

* Various doses of SnPP were injected subcutaneously to 5-day-old $j /$ + and $j / j$ Gunn rats and the effects of SnPP were examined at 30 days of life.

$\dagger p<0.01$ compared with nontreated $j / j$ rats. was observed (data not shown). Alternatively there could be a preferential effect of SnPP in nonhepatic tissues such as spleen and kidney. However, Anderson et al. (20) reported that SnPP administered intravenously accumulates in liver, spleen, and kidney with similar time-course profiles up to at least $12 \mathrm{~h}$, and 1-h levels of the inhibitor in these tissues are far larger than the $\mathrm{Ki}$ value. These authors also showed that heme oxygenase activities in liver, spleen, and kidney are inhibited in the same timedependent manner by SnPP administered subcutaneously.

Another possibility is that there are heme degradation pathways not mediated by heme oxygenase (25) and that unconjugated bilirubin may be catabolized by mixed-function monooxygenases (26). We cannot exclude an effect of SnPP to stimulate these pathways and accelerate the reduction of serum bilirubin. SnPP could be acting as a photosensitizer to enhance bilirubin destruction (27). This appears unlikely because the present experiments, including the assay for bilirubin, were performed under dim light. Finally, SnPP may act to displace bilirubin from the albumin-bilirubin complex and cause pigment deposition in tissues with a concomitant decrease of serum levels. Recently Breslow et al. (28) reported that the albumin-bilirubin binding is little affected by SnPP. However, they conducted their experiments in an in vitro system and it is not clear if the same is also true in vivo, particularly in hyperbilirubinemic Gunn rats.

Keino et al. (14) showed that the cerebellar hypoplasia of $j / j$ rats could be prevented by photoirradiation from postnatal day 5 to 10 and that this photo-effect was due to the reduction of serum bilirubin. Unlike phototherapy, the protective effect of SnPP (in a single dose of $20 \mu \mathrm{mol} / \mathrm{kg}$ ) on the cerebellar hypoplasia was relatively limited (15\% increase over the control; Table 2), although a significant response of serum bilirubin to SnPP was observed (Fig. 3). This contradiction may be explained by the long biological half-life of bilirubin in $j / j$ rats (24). Surprisingly the mortality rate of $j / j$ infants was most effectively reduced by the administration of SnPP at a dose of $5 \mu \mathrm{mol} / \mathrm{kg}$ of body weight (Table 2) and one-fifth of this dose also was effective in minimizing cerebellar hypoplasia (Table 2). The mechanism for the SnPP-induced decrease in mortality rate with only a limited effect on the cerebellar hypoplasia remains unclear.

\section{REFERENCES}

1. Lewis PJ, Friedman LA 1979 Prophylaxis of neonatal jaundice with maternal antipyrine treatment. Lancet 1:300-301

2. Segni G, Polidori G, Romagnoli C 1977 Bucolome in prevention of hyperbilirubinaemia in preterm infants. Arch Dis Child 52:549-550

3. Semba R, Sato H, Yamamura H 1978 Danger of bucolome in infants with hyperbilirubinaemia: experimental evidence. Arch Dis Child 53:503-505

4. Drummond GS, Kappas A 1982 Chemoprevention of neonatal jaundice: potency of tin-protoporphyrin in an animal model. Science 217:1250-1252

5. Drummond GS, Kappas A 1981 Prevention of neonatal hyperbilirubinemia by tin protoporphyrin $\overline{\mathrm{IX}}$, a potent competitive inhibitor of heme oxidation. Proc Natl Acad Sci USA 78:6466-6470

6. Cornelius CE, Rodgers PA 1984 Prevention of neonatal hyperbilirubinemia in rhesus monkeys by tin-protoporphyrin. Pediatr Res 18:728-730

7. Sassa S, Drummond GS, Bernstein SE, Kappas A 1983 Tin-protoporphyrin suppression of hyperbilirubinemia in mutant mice with severe hemolytic anemia. Blood 61:1011-1013

8. Sassa S, Drummond GS, Bernstein SE, Kappas A 1985 Long-term administration of massive doses of Sn-protoporphyrin in anemic mutant mice $\left(\mathrm{sph}^{\text {ha }}\right)$ $s p h^{h a}$ ). J Exp Med 162:864-876

9. Weatherill PJ, Kennedy SME, Burchell B 1980 Immunochemical comparison of UDP-glucuronyltransferase from Gunn- and Wistar-rat livers. Biochem J 191:155-163

10. Gunn CK 1938 Hereditary acholuric jaundice in a new mutant strain of rats. J Hered 29:137-139

11. Schutta HS, Johnson L 1967 Bilirubin encephalopathy in the Gunn rat: a fine structure study of the cerebellar cortex. J Neuropathol Exp Neurol 26:377396

12. Sawasaki Y, Yamada N, Nakajima H 1976 Developmental features of cerebellar hypoplasia and brain bilirubin levels in a mutant (Gunn) rat with hereditary hyperbilirubinaemia. J Neurochem 27:577-583

13. Sato H, Katoh-Semba R, Kashiwamata S 1977 Effect of irradiation on the erythrocyte membranes of homozygous Gunn rat sucklings. Biol Neonate 32:158-165

14. Keino H, Sato H, Semba R, Aono S, Aoki E, Kashiwamata S 1985-86 Mode of prevention by phototherapy of cerebellar hypoplasia in a new Sprague- 
Dawley strain of jaundiced Gunn rats. Pediatr Neurosci 12:145-150

15. Tenhunen R, Marver HS, Schmid R 1969 Microsomal heme oxygenase: characterization of the enzyme. J Biol Chem 244:6388-6394

16. Tenhunen R, Marver HS, Schmid R 1968 The enzymatic conversion of heme to bilirubin by microsomal heme oxygenase. Proc Natl Acad Sci USA 61:748-755

17. Katoh R, Kashiwamata S, Niwa F 1975 Studies on cellular toxicity of bilirubin: effect on the carbohydrate metabolism in the young rat brain. Brain Res 83:81-92

18. Lowry OH, Rosebrough NJ, Farr AL, Randall RJ 1951 Protein measurement with the folin phenol reagent. J Biol Chem 193:265-275

19. Malloy HT, Evelyn KA 1937 The determination of bilirubin with the photoelectric colorimeter. J Biol Chem 119:481-490

20. Anderson KE, Simionatto CS, Drummond GS, Kappas A 1984 Tissue distribution and disposition of the tin-protoporphyrin, a potent competitive inhibitor of heme oxygenase. J Pharmacol Exp Ther 228:327-333

21. Kappas A, Drummond GS, Sardana MK 1985 Sn-protoporphyrin rapidly and markedly enhances the heme saturation of hepatic tryptophan pyrrolase. $J$ Clin Invest 75:302-305

22. Simionatto CS, Anderson KE, Drummond GS, Kappas A 1985 Studies on the mechanism of Sn-protoporphyrin suppression of hyperbilirubinemia: inhibition of heme oxidation and bilirubin production. J Clin Invest 75:51352.1

23. Landaw SA, Sassa S, Drummond GS, Kappas A 1987 Proof that Sn-protoporphyrin inhibits the enzymatic catabolism of heme in vivo, suppression of ${ }^{14} \mathrm{CO}$ generation from radiolabeled endogenous and exogenous heme sources. J Exp Med 165:1195-1200

24. Schmid R, Hammaker L 1963 Metabolism and disposition of $\mathrm{C}^{14}$-bilirubin in congenital nonhemolytic jaundice. J Clin Invest 42:1720-1734

25. Bissell DM, Gunzelian PS 1980 Degradation of endogenous hepatic heme by pathways not yielding carbon monoxide: studies in normal rat liver and in primary hepatocyte culture. J Clin Invest 65:1135-1140

26. Kapitulnik J, Ostro JD 1977 Stimulation of bilirubin catabolism in jaundiced Gunn rats by an inducer of microsomal mixed-function monooxygenases. Proc Natl Acad Sci USA 75:682-685

27. McDonagh AF, Palma LA 1985 Tin-protoporphyrin: a potent photosensitizer of bilirubin destruction. Photochem Photobiol 42:261-264

28. Breslow E, Chandra R, Kappas A 1986 Biochemical properties of the heme oxygenase inhibitor, Sn-protoporphyrin: interactions with apomyoglobin and human albumin. J Biol Chem 261:3135-3141 